\title{
Editorial
}

\section{Doing it upside down}

Pensions (2010) 15, 243-244. doi:10.1057/pm.2010.27

The recent mass of reforms proposed, suggested or announced in Australia in relation to pensions systems shows evidence of attention-deficit hyperactivity disorder (ADHD). It is true that the Australian political system is struggling with the idea of coalition, that forest fires and endemic drought are a problem as are dingos and kangaroos. But even faced with all these challenges the country seems to find time to examine, discuss, amend, review and fiddle about interminably with their pensions system. What is it that makes them so continually discontented? Why could they not get it right first time?

The problems that face Australia are very similar to those faced, in different ways, by almost all developed and developing jurisdictions. Aging populations, unfavourable demographics, increasing longevity, reducing interest rates whatever the symptoms, they afflict almost everyone. But even those in a bit of a pickle, like France with a retirement of age of 60 years which is clearly insupportable, and the government's intended increase of which periodically draws France to a halt through strikes and public agitation, only attempts to make strategic reforms, rather than persistently tinkering. The best thing about the Australian continual review is the language they use; superannuation, invariably shortened to super, results in super-academics, super-actuaries, and of course super-lawyers.

Australia is a problem for the rest of the world because although they are a long way away from it, much of it watches what they do with interest. And given, for example, that much of the UK reform proposals (and in particular National Employment Savings Trust (NEST)) is based on the Australian thinking, it might be useful to look at what they are doing - with the thought that what happens there might eventually happen here. Around the world, countries are changing their systems - the Norwegians have just introduced a raft of simple and sensible reforms and are simply the latest. What is it that the Australians are doing that makes them rather different?

Their Super review $(2010)^{1}$ is a substantial piece of work, and to cover it in a short editorial is to do it an injustice (though not much). It has quite rightly come in for the kind of criticism that seems all too relevant to many countries' problems. The reason is that it attempts to micro-manage and micro-regulate the governance of superannuation schemes, and although its main report is relatively short (around 60 pages) there are 30 pages of detailed recommendations, together with a second very large volume.

One part of it, dealing with what the UK regulator is also fascinated with at present, is scoping the governance of schemes. The Australians separately considered trustee and investment governance. They want to codify the duties of trustees of schemes (for example, including a requirement to act honestly, as though such a statutory requirement were needed). It thinks that chairmen of trustees should be held to a higher standard than other trustees, and be subject to special training. It wants gender and diversity requirements. It wants trustees to warrant skill sets to be demonstrated by trustees within 12 months of appointment. And it contains a list of trustee management objectives of the sort weekly parodied by journalist and novelist Lucy Kellaway in the United Kingdom in the Financial Times in her Monday morning slot.

Why it seems ridiculous is because it tries to reduce to writing and box-ticking what most trustees know they should do through common sense (and perhaps half-an-hour's trustee training) 
and makes unimaginably complicated what is quite a simple job - looking after other's people's money to a higher standard than if it were our own. The compliance (and more importantly the costs of checking the compliance) will be astonishing. What is not explored in the report is whether and to what degree the imposition of this fantastic superstructure would improve the level of benefits for members, and their security and confidence in the system. For example, the United Kingdom has had several decades of financial regulation, and financial regulators, and it did not prevent the GP Noble schemes being raped of around $\mathcal{E}^{5} 50$ million before the police intervened. Ironically, the alleged planner of the UK pension scheme fraud fled to Australia for safety (which may have been for him the wrong country from an extradition or civil liability point of view).

The Australian situation, which reflects the UK situation in the frequency of review, and the lack of holistic and strategic thinking, and lack of regulatory proportionality, is truly horrible. They, like the United Kingdom, cannot forbear for forever thinking that a long-term system needs interminable and continual revision and change; the phrases 'digging' and 'daisies' comes to mind. They, like the United Kingdom, struggle to find the right balance between reform and continuity which long-term projects like pensions need to in order to flourish. Observers and policymakers should be grateful for the Australian review in showing the rest of us not how to do it. These changes make it hard to communicate to the public how their pension system works, how consumer protection should operate, how the benefits are calculated and how the market is intended to respond to the increasing needs for protection in older age. They are a recipe for confusion, and they result mostly from a lack of joined up thinking in the original policy background to the original changes.

Not content with thinking about a major series of revision to the super system, Australian regulators have suddenly fixed upon changes to the supervision and governance of super schemes. They also have produced a sheaf of papers and discussion documents. They explore whether there should be an expansion of guidance for superannuation licensees in the areas of capital, risk management, adequacy of resources and fitness and propriety. None of the proposals explore, even in a flawed way, proportionality, need, cost or unintended consequences.

Pensions around the world used to be boring. We need to try very hard to make them tedious beyond belief again, and free from those distressed souls who seem to find themselves in government suffering from that horrible affliction of ADHD.

\section{FURTHER READING}

1 Australian Government. (2010) Review into the governance efficiency, structure and operation of Australia's superannuation system. 30 June, 2 volumes, http://www.supersystemreview .gov.au.

2 Independent Trustee Services Ltd v. Anthony John Morris [2010] NSWSC 847; [2010] 84 PBLR (4 August 2010, Sydney).

3 CGU Insurance v. Corrections Corporation of Australia [2010] 005 PBLR, [2008] FCAFC 173 (Australia: Federal Court: Victoria District Registry: Melbourne) 2008 October 21) (Investments Diversification - Defined contribution scheme - Whether insufficient diversification - Claim by members against sponsor - Whether insurance protection against liability).

4 Australian Prudential Regulation Authority. (2010) Response to Submissions: Guidance for Superannuation Licensees: Capital, Risk Management, Adequacy of Resources and Fitness and Propriety. Canberra: APRA.

5 Australian Prudential Regulation Authority. (2010) Prudential Practice Guide. SPG 200 Risk Management, August.

6 Australian Prudential Regulation Authority. (2010) Prudential Practice Guide. SPG 110 Capital, August.

7 Australian Prudential Regulation Authority. (2010) Prudential Practice Guide. SPG 230 Adequacy of resources, August.

8 Australian Prudential Regulation Authority. (2010) Prudential Practice Guide. SPG 520 Fitness and propriety, August http://www.apra.gov.au.

9 Coalition policy disappoints, Don't let down Australian workers Mr Abbott, Joint AIST/ASFA/FSC statement, The Association of Superannuation Funds of Australia (ASFA), the Australian Institute of Superannuation Trustees (AIST) and the Financial Services Council (FSC), Press release August, http://www.aist asn.au.

Robin Ellison 